\title{
The Equity Premium and Inflation: Evidence from the US
}

\author{
Samih Antoine Azar ${ }^{1}$ \\ ${ }^{1}$ Faculty of Business Administration \& Economics, Haigazian University, Beirut, Lebanon. \\ Correspondence: Samih Antoine Azar, Professor, Faculty of Business Administration \& Economics, Haigazian \\ University, Mexique Street, Kantari, Beirut, Lebanon.
}

Received: December 24, 2014

Accepted: December 31, 2014

Available online: January 22, 2015

doi:10.11114/afa.v1i1.618

URL: http://dx.doi.org/10.11114/afa.v1i1.618

\begin{abstract}
There is recent and strong evidence that nominal stock returns are independent of inflation. In what amounts to the same thing, when real stock returns are regressed on inflation the resulting estimated coefficient on inflation is negative and unitary. These two propositions are mathematically equivalent. The purpose of this paper is to show that the market stock return is also independent of expected inflation, as measured by the T-bill rate. Firstly, regressions of the equity premium on inflation produce invariably slope coefficients that are statistically insignificantly different from -1 . The inflation variable on the right hand side of the regression picks up the sign and the magnitude of the T-bill rate in the equity premium on the left hand side of the regression. This is as expected because the T-bill rate is an unbiased predictor of the future inflation rate, or, in other terms, the T-bill rate is a proxy for expected inflation. Hence regressions of real stock returns on inflation are in substance the same as regressions of the equity premium on inflation, and in both cases nominal stock returns are independent of inflation, and of its expected proxy, the T-bill rate. Secondly, additional evidence is provided from regressions of stock market returns on the inflation rate and the T-bill rate taken together. The hypothesis that the sum of the two coefficients on these two variables is statistically insignificantly different from zero is strongly supported. Moreover, the joint null hypothesis that the first coefficient is equal to -1 and that the second coefficient is equal to +1 is also strongly supported. As a conclusion stock prices already reflect macroeconomic shocks and there is neither money illusion nor over and under adjustment on the part of investors.
\end{abstract}

Keywords: equity premium, inflation, T-bill rate, spurious negative relation, robust standard errors, EGARCH, quantile regressions, robust least squares, Markov switching regressions.

\section{Introduction}

This paper has the purpose to study the relation between the equity premium and the inflation rate in the case of the United States. This relation has not received all the attention that it deserves. Exceptions are Yaansah and Peasnell (1994), Kyriacou et al. (2006), Beirne and de Bondt (2008), and Madsen and Dzhumasher (2009). The literature has mostly covered the relations between nominal and real stock returns with inflation. Recent evidence finds that nominal stock returns are independent of inflation (Azar, 2010, 2014a, 2014b). When real stock returns are considered the coefficient on the inflation rate is insignificantly different from -1 in line with the fact that the inflation rate enters as a negative and as a unitary term in the construction of the dependent variable. This means that the inflation rate, as an independent variable, picks up the effect of the inflation rate as part of the dependent variable. Mathematically this can be shown as follows:

$$
\tilde{r}_{t}-\pi_{t}=\alpha-\beta \pi_{t}+\varepsilon_{t} \text { but since } \beta=1 \text { then } \tilde{r}_{t}-\pi_{t}=\alpha-\pi_{t}+\varepsilon_{t} \Rightarrow \tilde{r}_{t}=\alpha+\varepsilon_{t}
$$

where $\tilde{r}$ is the risky stock market return, $\pi$ is actual inflation, $\varepsilon$ is a well-behaved noise variable, $t$ is the time period, and $\alpha$ and $\beta$ are regression coefficients.

The paper is organized as follows. In the second section the theoretical background is expounded and a short survey of the literature is presented. In section 3 the empirical studies are furnished. In this section ten different specifications of the underlying relation are estimated. The results are repeated with equity returns calculated in continuous terms as first differences of the logs. Finally regressions of the equity return on both inflation and the T-bill rate are run. The intent is to show that (1) the sum of the coefficients on these two variables is zero and (2) the first coefficient is insignificantly different from -1 together with the second coefficient being insignificantly different from +1 . This dual intent is corroborated and it is shown that the equity premium is always independent of the inflation rate even when different 
specifications are posited. The final section summarizes and concludes.

\section{The Theory}

The equity premium is the excess of the market stock return over the T-bill rate. If this premium is regressed over the inflation rate then, as long as the inflation rate and the T-bill rate are proportional to each other, then the regression should produce a coefficient of -1 on the inflation rate similar to the demonstration in equations (1), and similar to the demonstration that follows:

$$
\tilde{r}_{t}-i_{t}=\alpha-\beta \pi_{t}+\varepsilon_{t} \text { but since } \beta=1 \text { and } \pi_{t}=i_{t}+\xi_{t} \text {, then } \tilde{r}_{t}-i_{t}=\alpha-i_{t}-\xi_{t}+\varepsilon_{t} \Rightarrow \tilde{r}_{t}=\alpha-\xi_{t}+\varepsilon_{t}
$$

In equations (2) $i$ is the T-bill rate and $\xi$ is a well-behaved noise parameter, and the strong assumption that $\pi_{t}=i_{t}+\xi_{t}$ is made. This assumption stems from the empirical fact that short term interest rates are unbiased predictors of future inflation rates (Fama, 1975). Equations (2) show that a regression of the equity premium on inflation should result in a negative and a unitary coefficient on the inflation rate.

Yaansah and Peasnell (1994) find a weak negative relation between the equity premium and inflation. Sharpe (2002) finds no relation between expected inflation and the equity premium. Kyriacou et al. (2006), Beirne and de Bondt (2008), and Madsen and Dzhumasher (2009) find a positive and statistically significant relation between inflation and the equity premium. For these latter authors this positive relation explains why the ex post equity risk premium was so high before the 1980s, and they argue that without the effect of inflation there is no longer a risk premium puzzle as propounded in Mehra and Prescott (1985). Kyriacou et al. (2006) and Beirne and de Bondt (2008) use this positive relation to make the deduction that the equity premium was so high in most of the $20^{\text {th }}$ century because of the higher inflationary background during that period. Madsen and Dzhumasher (2009) reason that inflation was mostly unexpected before the 1960s, reducing the yield on bonds, and consequently increasing the ex post risk premium. They call this the ex post bias. Without this anomalous effect of inflation the risk premium is much lower and falls to between $3.3 \%$ and $4.4 \%$. It seems that the relation between the market premium and inflation has undergone a shift after the 1950s, from a positive relation before the 1950s to a negative relation thereafter as will be shown below. In fact if real stock returns are negatively related to inflation it follows that the equity premium must also be negatively related to inflation. There is a strong efficiency argument for the irrelevance of inflation and of expected inflation. Since equity prices are equal to discounted future cash flows, a higher inflation, or a higher expected inflation, raises the nominal cash flows in the numerator and increase the denominator by anadditional inflation premium, leaving present values and stock prices unaffected.

\section{The Empirical Analysis}

All data are retrieved form the web site of the Federal Reserve Bank of Saint Louis and span the monthly period from February 1957 to September 2014, with 692 observations per variable. Three variables are identified (1) the website monthly "Total Share Prices for All Shares for the United States" as a measure for the stock market index, (2) the website monthly consumer price index (CPI) for all items from which the inflation rate is computed, and (3) the website monthly secondary market yield of the 3-month T-bill.

Table 1 presents the empirical results of carrying out regressions of the equity premium on the inflation rate. The market stock return in the equity premium is calculated via two methods: as a percentage return and as a continuously compounded return, by taking the first difference of the logs. The inflation rate is continuously compounded by taking the first difference of the logs. Ten different specifications are modeled. The first is a straight ordinary least squares (OLS). The second is OLS with heteroscedasticity and autocorrelation consistent (HAC) robust standard errors (Newey and West, 1987). The third is with an EGARCH model of the conditional variance (Nelson, 1991). The fourth is also with an EGARCH model but with Bollerslev-Wooldridge robust standard errors (Bollerslev and Wooldridge, 1992). The fifth, the sixth, and the seventh are with robust least squares (Huber, 1973, 1981), adjusting for outliers in the dependent variable (M-estimation), for outliers in the independent variables (S-estimation), and for outliers in both the dependent and the independent variables (MM-estimation). The eighth regression is with a quantile regression on the median (Koenker and Basset, 1978; Basset and Koenker, 1982; Koenker, 1994; Koenker and Machado, 1999; and Koenker, 2005). The ninth and tenth are Markov switching regressions with regime-specific variances, and with robust standard errors for the last regression (Goldfeld and Quandt, 1973, 1976; Maddala, 1986; Hamilton, 1990, 1994; Frühwirth-Schnatter, 2006).

Out of a total of 24 regressions 17 regressions give a statistically significant and negative coefficient on inflation. See Table 1. For these 17 regressions the minimum absolute t-statistic is 2.136376 and the maximum is 5.793103 . At face value this is quite strong evidence that there is a negative relation between inflation and the equity premium contrary to previous studies on the subject. However, what is surprising is that all the estimated slopes on the inflation variable whether they are significantly negative or otherwise are consistently statistically insignificantly different from -1 . The lowest actual p-value for the null hypothesis of a negative unitary coefficient is 0.0519 , and the highest is 0.8311 . The 
two variants of the equity premium afford the same results. The actual p-values for the null hypothesis that the slope is equal to -1 are in brackets in Table 1 below the t-statistics of the slope coefficients. Overall this is fairly strong evidence for the hypothesis of this paper that the inflation variable is picking up the effect of the T-bill rate, leaving market stock returns unaffected by inflation.

Table 1. Regressions of the Market Stock Premium on the Continuously Compounded Inflation Rate

\begin{tabular}{|c|c|c|c|c|}
\hline \multirow[t]{2}{*}{ Dependent variable $\rightarrow$} & \multicolumn{2}{|c|}{$\Delta\left(\ln \left(\right.\right.$ index $\left.\left._{\mathrm{t}}\right)\right)-(\mathrm{TB} 3 / 1200)$} & \multicolumn{2}{|c|}{$\left(\Delta\left(\right.\right.$ index $\left._{\mathrm{t}}\right) /$ index $\left._{\mathrm{t}-1}\right)-(\mathrm{TB} 3 / 1200)$} \\
\hline & Constant & Slope on $\Delta\left(\ln \left(\right.\right.$ cpi $\left.\left._{t}\right)\right)$ & Constant & Slope on $\Delta\left(\ln \left(\right.\right.$ cpi $\left.\left._{t}\right)\right)$ \\
\hline Ordinary least squares (OLS) & $\begin{array}{c}0.004773 \\
(2.452822)\end{array}$ & $\begin{array}{c}-1.094224 \\
(2.476556) \\
{[0.8311]}\end{array}$ & $\begin{array}{c}0.005563 \\
(2.896625)\end{array}$ & $\begin{array}{c}-1.135018 \\
(2.602596) \\
{[0.7569]}\end{array}$ \\
\hline $\begin{array}{l}\text { OLS with Newey-West } \\
\text { robust standard errors }\end{array}$ & $\begin{array}{c}0.004773 \\
(1.279975)\end{array}$ & $\begin{array}{c}-1.094224 \\
(1.166666) \\
{[0.9200]}\end{array}$ & $\begin{array}{c}0.005563 \\
(1.581736)\end{array}$ & $\begin{array}{c}-1.135018 \\
(1.282878) \\
{[0.8787]}\end{array}$ \\
\hline EGARCH & $\begin{array}{c}0.006480 \\
(3.687315)\end{array}$ & $\begin{array}{c}-1.389796 \\
(3.573692) \\
{[0.3162]}\end{array}$ & $\begin{array}{c}0.006789 \\
(3.926914)\end{array}$ & $\begin{array}{c}-1.317389 \\
(3.435537) \\
{[0.4078]}\end{array}$ \\
\hline $\begin{array}{l}\text { EGARCH with Bollerslev-Wooldridge robust } \\
\text { standard errors }\end{array}$ & $\begin{array}{c}0.006480 \\
(3.924281)\end{array}$ & $\begin{array}{c}-1.389796 \\
(3.377995) \\
{[0.3434]}\end{array}$ & $\begin{array}{c}0.006789 \\
(4.197657)\end{array}$ & $\begin{array}{c}-1.317389 \\
(3.275084) \\
{[0.4301]}\end{array}$ \\
\hline Robust least squares: M-estimation & $\begin{array}{c}0.009581 \\
(5.744677)\end{array}$ & $\begin{array}{c}-1.699981 \\
(4.488558) \\
{[0.0646]}\end{array}$ & $\begin{array}{c}0.009766 \\
(5.793103)\end{array}$ & $\begin{array}{c}-1.744215 \\
(5.793103) \\
{[0.0519]}\end{array}$ \\
\hline Robust least squares: S-estimation & $\begin{array}{c}0.012630 \\
(5.059826)\end{array}$ & $\begin{array}{c}-1.328104 \\
(2.343203) \\
{[0.5627]}\end{array}$ & $\begin{array}{c}0.013008 \\
(5.117399)\end{array}$ & $\begin{array}{c}-1.641624 \\
(2.844003) \\
{[0.2663]}\end{array}$ \\
\hline $\begin{array}{l}\text { Robust least squares: } \\
\text { MM-estimation }\end{array}$ & $\begin{array}{c}0.009582 \\
(5.745443)\end{array}$ & $\begin{array}{c}-1.696635 \\
(4.480192) \\
{[0.0658]}\end{array}$ & $\begin{array}{c}0.009769 \\
(5.796390)\end{array}$ & $\begin{array}{c}-1.738741 \\
(4.543531) \\
{[0.0536]}\end{array}$ \\
\hline Quantile regression (median) & $\begin{array}{c}0.010471 \\
(4.852560)\end{array}$ & $\begin{array}{c}-1.829079 \\
(2.795616) \\
{[0.2051]}\end{array}$ & $\begin{array}{c}0.010549 \\
(4.828934)\end{array}$ & $\begin{array}{c}-1.839869 \\
(2.787391) \\
{[0.2032]}\end{array}$ \\
\hline \multicolumn{5}{|l|}{$\begin{array}{l}\text { Markov switching regression with } \\
\text { regime-specific variances: }\end{array}$} \\
\hline$*$ regime 1 & $\begin{array}{c}0.012763 \\
(6.577544)\end{array}$ & $\begin{array}{c}-1.760105 \\
(0.555201 \\
[0.1710])\end{array}$ & $\begin{array}{l}-0.019070 \\
(2.680114)\end{array}$ & $\begin{array}{c}0.599016 \\
(0.623369) \\
{[0.0961]}\end{array}$ \\
\hline *regime 2 & $\begin{array}{l}-0.013518 \\
(2.012933)\end{array}$ & $\begin{array}{c}0.362036 \\
(0.343956) \\
{[0.1957]}\end{array}$ & $\begin{array}{c}0.012416 \\
(6.662271)\end{array}$ & $\begin{array}{c}-1.655685 \\
(3.208883) \\
{[0.2038]}\end{array}$ \\
\hline \multicolumn{5}{|l|}{$\begin{array}{l}\text { Markov switching regression with } \\
\text { regime-specific variances and robust standard } \\
\text { errors: }\end{array}$} \\
\hline$*$ regime 1 & $\begin{array}{c}0.012763 \\
(5.786415)\end{array}$ & $\begin{array}{c}-1.760105 \\
(2.162993) \\
{[0.3503]}\end{array}$ & $\begin{array}{l}-0.019070 \\
(1.082689)\end{array}$ & $\begin{array}{c}0.598293 \\
(0.212867) \\
{[0.5696]}\end{array}$ \\
\hline$*$ regime 2 & $\begin{array}{l}-0.013518 \\
(1.168135)\end{array}$ & $\begin{array}{c}0.362036 \\
(0.218545) \\
{[0.4110]}\end{array}$ & $\begin{array}{c}0.012416 \\
(6.070583)\end{array}$ & $\begin{array}{c}-1.654889 \\
(2.136376) \\
{[0.3979]}\end{array}$ \\
\hline
\end{tabular}

Notes: Index is the market share price. TB3 is the T-bill rate in the secondary market. $\Delta$ is the first-difference operator. Absolute t-statistics are in parenthesis. Actual p-values for the null hypothesis that the slope is equal to -1 are in brackets.

The statistics in Table 2 depend on the regression of the equity return on the inflation rate and on the 3-month T-bill rate together. From equations (2) one has that:

$$
\tilde{r}_{t}-i_{t}=\alpha-\beta \pi_{t}+\varepsilon_{t} \Rightarrow \tilde{r}_{t}=\alpha+i_{t}-\beta \pi_{t}+\varepsilon_{t} \Rightarrow \tilde{r}_{t}=\alpha+i_{t}-\pi_{t}+\varepsilon_{t} \text { because } \beta \approx 1
$$

The first null hypothesis is that the sum of the two coefficients on the two independent variables, the T-bill rate and the inflation rate $\left(i_{t}\right.$ and $\left.\pi_{t}\right)$, is zero. If this sum is statistically insignificantly different from zero then this is additional evidence that the inflation rate is picking up the effect of the T-bill rate in the equity premium. Again two formulae for the equity return are used: from arithmetic percentage values to geometric difference-of-logs values. The actual p-values reported in parenthesis in Table 2 for the above null hypothesis give the following results: at the 5\% two-tailed marginal significance level 10 tests reject the null and 14 tests fail to reject the null. The second joint null hypothesis is that the first coefficient, on the T-bill rate, is insignificantly different from +1 , and that the second coefficient, on the inflation rate, is insignificantly different from -1 . The actual p-values reported in brackets in Table 2 for this joint null hypothesis 
give the following results: at the 5\% two-tailed marginal significance level 12 tests reject the null and 12 tests fail to reject the null.

Table 2. Evaluation of regressions of stock market returns on the continuously compounded inflation rate and on the monthly TB3 rate. The figures in parenthesis are for the actual p-values under the null hypothesis that the sum of the two coefficients on the above two last variables is zero. The figures in brackets are for the actual p-values under the null hypothesis that the two respective coefficients are jointly equal to -1 and +1 .

\begin{tabular}{|c|c|c|}
\hline Dependent variable $\rightarrow$ & $\Delta\left(\ln \left(\right.\right.$ index $\left.\left._{t}\right)\right)$ & $\left(\Delta\left(\right.\right.$ index $\left._{t}\right) /$ index $\left._{t-1}\right)$ \\
\hline Ordinary least squares (OLS) & $(0.1504)[0.1329]$ & $(0.1340)[0.1353]$ \\
\hline OLS with Newey-West & $(0.3793)[0.2068]$ & $(0.3422)[0.2173]$ \\
\hline \multicolumn{3}{|l|}{ robust standard errors } \\
\hline EGARCH & $(0.0710)[0.2038]$ & $(0.0896)$ [0.4185] \\
\hline $\begin{array}{l}\text { EGARCH with Bollerslev-Wooldridge robust } \\
\text { standard errors }\end{array}$ & $(0.0616)[0.1524]$ & $(0.1732)[0.3766]$ \\
\hline Robust least squares: M-estimation & (0.0090) [0.0323] & $(0.0083)[0.0302]$ \\
\hline Robust least squares: S-estimation & $(0.0153)[0.0361]$ & $(0.0092)[0.0251]$ \\
\hline Robust least squares: & $(0.0097)[0.0343]$ & $(0.0086)[0.0311]$ \\
\hline \multicolumn{3}{|l|}{ MM-estimation } \\
\hline Quantile regression (median) & (0.0230) [0.0180] & (0.0220) [0.0172] \\
\hline \multicolumn{2}{|l|}{$\begin{array}{l}\text { Markov switching regression with } \\
\text { regime-specific variances: }\end{array}$} & (0.0139) [0.0000] \\
\hline *regime 2 & $(0.7250)[0.2172]$ & $(0.7307)[0.1891]$ \\
\hline \multicolumn{3}{|l|}{$\begin{array}{l}\text { Markov switching regression with } \\
\text { regime-specific variances and robust standard } \\
\text { errors: }\end{array}$} \\
\hline$*$ regime 1 & $(0.1185)[0.0000]$ & $(0.1017)[0.0000]$ \\
\hline regime 2 & $(0.7486)[0.4507]$ & $(0.7535)[0.2871]$ \\
\hline
\end{tabular}

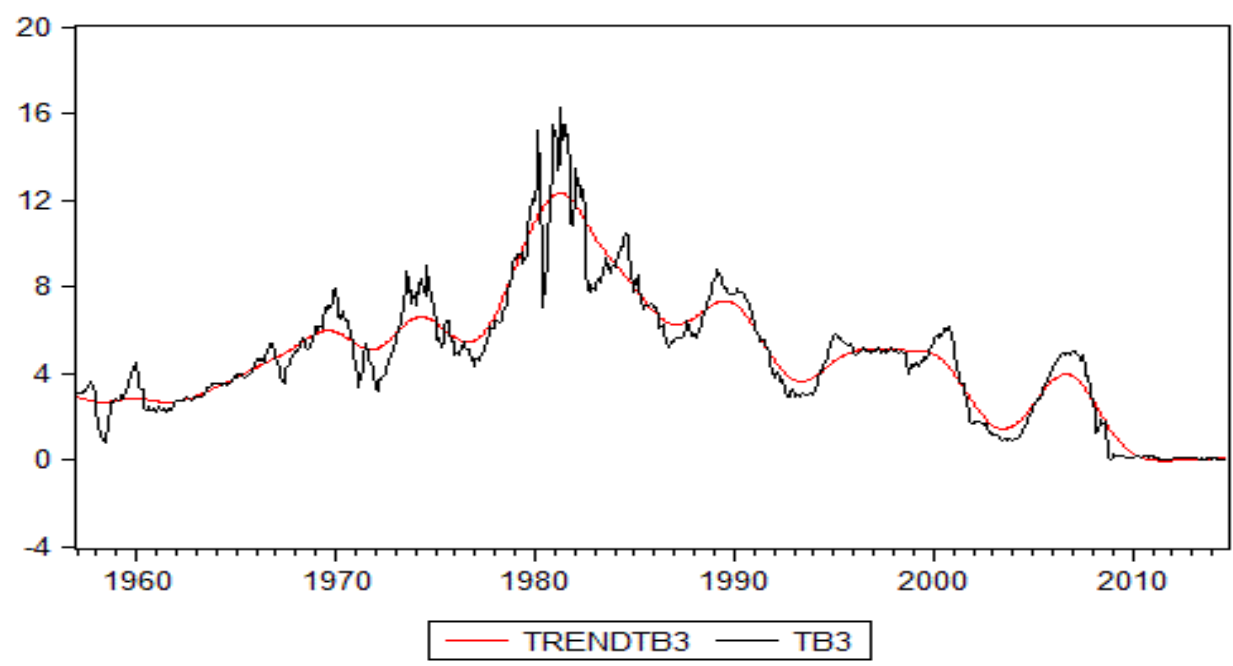

However, there is an econometric problem in these tests. While the inflation rate is stationary the 3-month T-bill rate is found to be non-stationary although it is against theory for the marginal product of capital to be non-stationary. To remedy this problem a Hodrick-Prescott filter is applied on the T-bill series, and the trend filter is calculated. The results of comparing the filtered (TRENDTB3) and the non-filtered (TB3) data series is found in the figure above which draws the two series on the same graph. It should be mentioned that cointegration analysis and vector error-correction models cannot be performed because there is only one variable that is found to be non-stationary, which is the T-bill rate. All other variables are stationary in distribution.

In Table 3 the results of testing the same two null hypotheses as earlier are presented, with the inclusion in the regressions of the filtered T-bill series, instead of the raw T-bill series. The first null of a zero sum of the two coefficients on the independent variables is rejected in only 2 tests out of 24 at the $5 \%$ marginal significance level. These two rejections occur with the S-estimation of robust least squares, which adjusts for outliers in the independent 
variables. Since for the MM-estimation of robust least squares which adjust for outliers in both the dependent and the independent variables these same null hypotheses are not rejected this is strong evidence that the results of the S-estimation are mainly due to sampling error.

The second joint null hypothesis that the first coefficient, on the inflation rate, is insignificantly different from -1 , and that the second coefficient, on the T-bill rate, is insignificantly different from +1 , is rejected in only one test out of 24 at the 5\% marginal significance level. Again this rejection occurs with the S-estimation of robust least squares, which adjusts for outliers in the independent variables. Since for the MM-estimation of robust least squares which adjust for outliers in both the dependent and the independent variables the same null hypotheses are not rejected this is strong evidence that the result of the S-estimation is mainly due to sampling error. As a conclusion the evidence is very strong that the equity premium and the inflation rate are related together just for the reason that the inflation rate picks up the effect of the T-bill rate in the formulation of the equity premium.

Table 3. Evaluation of the regressions of stock returns on the continuously compounded inflation rate and on the monthly TB3 rate, filtered by the Hodrick-Prescott rule. The figures in parenthesis are for the actual p-values under the null hypothesis that the sum of the two coefficients on the above two last variables is zero. The figures in brackets are for the actual $\mathrm{p}$-values under the null hypothesis that the two respective coefficients are jointly equal to -1 and +1 .

\begin{tabular}{|c|c|c|}
\hline Dependent variable $\rightarrow$ & $\Delta\left(\ln \left(\right.\right.$ index $\left.\left._{t}\right)\right)$ & $\left(\Delta\left(\right.\right.$ index $\left._{t}\right) /$ index $\left._{t-1}\right)$ \\
\hline Ordinary least squares (OLS) & (0.8994) [0.9917] & $(0.8769)$ [0.9849] \\
\hline OLS with Newey-West & $(0.9371)[0.9957]$ & $(0.9214)[0.9951]$ \\
\hline \multicolumn{3}{|l|}{ robust standard errors } \\
\hline EGARCH & $(0.5969)[0.7144]$ & $(0.6835)[0.6943]$ \\
\hline EGARCH with Bollerslev-Wooldridge robust & $(0.5451)[0.7346]$ & $(0.6451)[0.7468]$ \\
\hline \multicolumn{3}{|l|}{ standard errors } \\
\hline Robust least squares: M-estimation & $(0.2149)[0.2143]$ & $(0.2065)[0.1889]$ \\
\hline Robust least squares: S-estimation & $(0.0313)[0.0887]$ & $(0.0137)[0.0451]$ \\
\hline Robust least squares: & $(0.2201)[0.2328]$ & $(0.2079)[0.1987]$ \\
\hline \multicolumn{3}{|l|}{ MM-estimation } \\
\hline Quantile regression (median) & $(0.1589)[0.3647]$ & $(0.1581)[0.3646]$ \\
\hline \multicolumn{3}{|l|}{ Markov switching regression with } \\
\hline \multicolumn{3}{|l|}{ regime-specific variances: } \\
\hline$*$ regime 1 & $(0.1444)[0.2452]$ & $(0.1193)[0.3873]$ \\
\hline *regime 2 & $(0.1727)[0.3976]$ & $(0.1162)[0.1902]$ \\
\hline \multicolumn{3}{|l|}{ Markov switching regression with } \\
\hline \multicolumn{3}{|l|}{ regime-specific variances and robust standard } \\
\hline \multicolumn{3}{|l|}{ errors: } \\
\hline$*$ regime 1 & $(0.1840)[0.4462]$ & $(0.3154)[0.6396]$ \\
\hline *regime 2 & $(0.3445)[0.6581]$ & $(0.1488)[0.3880]$ \\
\hline
\end{tabular}

\section{Conclusion}

This paper tests the relation between the equity premium and inflation in the US. Ten different regression specifications are estimated. The equity return in the equity premium is calculated with percentage changes and with the difference of the logs. The relation between equity returns and inflation is mostly negative and statistically significant. The paper argues that this negative effect, which turns out to be insignificantly different from - 1 for all regressions, is due to the fact that the inflation variable picks up the negative effect of the T-bill rate in the construction of the equity premium (Table 1). To provide further evidence on this the equity return is regressed on both the inflation rate and the T-bill rate. The null hypothesis that the sum of the coefficients on these two independent variables is zero is rejected for 10 out of 24 tests (Table 2). The joint null hypothesis that the first coefficient is equal to -1 , and that the second coefficient is equal to +1 , is rejected for 12 out of 24 tests (Table 2). The probable reason for these rejections is the apparent non-stationary behavior of the T-bill rate. When the latter is filtered and its trend variations are calculated, and included in the regressions in place of the raw series, the number of rejections falls to only 2 out of 24 for the first null hypothesis, and falls to only 1 out of 24 for the second null hypothesis (Table 3). Moreover these three rejections are due to 
sampling error because they arise from adjusting for the outliers of the independent variables and are supplanted by encompassing regressions that adjust for the outliers of both dependent and independent variables, and that fail to reject the first and second nulls. The general conclusion is forceful: the equity premium is spuriously related to the inflation rate and equity returns are independent of both the inflation rate and the T-bill rate. This conclusion has a corollary that the stock market is highly rational because stock prices already incorporate all information present in contemporaneous macroeconomic shocks, and that there is neither money illusion nor over or under adjustment. Since equity prices are equal to the present value of future cash flows a higher inflation, or a higher expected inflation, raises nominal cash flows in the numerator and increase the discount rate by an additional inflation premium in the denominator, leaving present values and equity prices unaffected.

\section{References}

Azar, S. A. (2010). Inflation and stock returns, International Journal of Accounting and Finance, 2(3-4), 254-274. http://dx.doi.org/10.1504/IJAF.2010.034399.

Azar, S. A. (2014a). The Determinants of US Stock Market Returns, Open Economics and Management Journal, 1, 1-13. http://dx.doi.org/10.2174/2352630001401010001

Azar, S. A. (2014b). Inflation and stock returns II, International Journal of Economics and Finance, 6(1), 208-216. http://dx.doi.org/10.5539/ijef.v6n1p208

Basset, G. Jr., \& Koenker, R. (1982). An empirical quantile function for linear models with i.i.d. errors, Journal of the American Statistical Association, 77(378), 407-415. http://dx.doi.org/10.1080/01621459.1982.10477826

Beirne, J., \& de Bondt, g. (2008). The equity premium and inflation. Applied Financial Economics Letters, 4(6), 439-442. http://dx.doi.org/10.1080/17446540801935389

Bollerslev, T., \& Wooldridge, J. M. (1992). Quasi-maximum likelihood estimation and inference in dynamic models with time varying covariances. Econometric Reviews, 11, 143-172. http://dx.doi.org/10.1080/07474939208800229

Fama, E., \& French, K. (2002). The equity premium, Journal of Finance, 57(2), 637-659. http://dx.doi.org/10.1111/1540-6261.00437

Frühwirth-Schnatter, S. (2006). Finite mixture and Markov switching models. New York: Springer Science + Business Media LLC.

Goetzmann, W. N., \& Ibbotson, R. G. (2006). The equity risk premium, essays and explorations. New York: Oxford University Press.

Goldfeld, S. M., \& Quandt, R. E. ( 1973). A Markov model for switching regressions. Journal of Econometrics, 3-16. http://dx.doi.org/10.1016/0304-4076(73)90002-X

Goldfeld, S. M., \& Quandt, R. E. (1976). Studies in nonlinear estimation. Cambridge, MA: Ballinger.

Hamilton, J. D. (1990). Analysis of time series subject to changes in regime. Journal of Econometrics, 45, 39-70. http://dx.doi.org/10.1016/0304-4076(90)90093-9

Hamilton, J. D. (1994). Time series analysis. Princeton: Princeton University Press.

Huber, P. J. (1973). Robust regression: asymptotics, conjectures and Monte Carlo, The Annals of Statistics, 1(5), 799-821. http://dx.doi.org/10.1214/aos/1176342503

Huber, P. J. (1981). Robust statistics. New York: John Wiley \& Sons. http://dx.doi.org/10.1002/0471725250

Koenker, R. (1994). Confidence intervals for regression quantiles. In Asymptotic statistics, Mandl, P. \& Huskova, H. (eds) New York: Springer-Verlag, 349-359. http://dx.doi.org/10.1007/978-3-642-57984-4_29

Koenker, R. (2005). Quantile regression. New York: Cambridge University Press. http://dx.doi.org/10.1017/CBO9780511754098

Koenker, R., \& Basset, G. Jr. (1978). Regression quantiles. Econometrica, 46(1), 33-50. http://dx.doi.org/10.2307/1913643

Koenker, R., \& Machado, J. A. F. (1999). Goodness of fit and related inference processes for quantile regression. Journal of the American Statistical Association, 94(448), 1296-1310. http://dx.doi.org/10.1080/01621459.1999.10473882

Kyriacou, J. B., Madsen, J. B., \& Mase, B. (2006). Does inflation exaggerate the equity premium? Journal of Economic Studies, 33(5), 344-356. http://dx.doi.org/10.1108/01443580610706573

Maddala, G. S. (1986). Disequilibrium, self-selection, and switching models, Handbook of econometrics, Griliches, Z. \& Intriligator, M. D. (eds), Amsterdam: North-Holland. 
Madsen, J. B., \& Dzhumashev, R. (2009). The equity premium and the ex post bias, Applied Financial Economics, 19, 157-174. http://dx.doi.org/10.1080/09603100701765174

Mehra, R. (ed) (2008). Handbook of the equity risk premium. Amsterdam: Elsevier. http://dx.doi.org/10.1016/B978-044450899-7.50006-3

Mehra, R., \& Prescott, E. C. (1985). The equity premium: a puzzle. Journal of Monetary Economics, 15, $145-161$. http://dx.doi.org/10.1016/0304-3932(85)90061-3

Nelson, D. B. (1991). Conditional heteroskedasticity in asset pricing: a new approach. Econometrica, 59, 347-370. http://dx.doi.org/10.2307/2938260

Newey, W. K., \& West, K. D. (1987). A Simple, positive semi-definite, heteroskedasticity and autocorrelation-consistent covariance matrix. Econometrica, 55, 703-708. http://dx.doi.org/10.2307/1913610

Sharpe, S. A. (2002). Reexamining stock valuation and inflation: the implications of analysts' earnings forecasts. The Review of Economics and Statistics, 84(4), 632-648. http://dx.doi.org/10.1162/003465302760556468

Yaansah, R. A., \& Pleasnell, K. V. (1994) Expectations, security yields, and inflation: ex-ante risk premia on UK shares, corporate bonds and gilts, 1969-1987, Journal of Business Finance \& Accounting, 21(2), 155-174. http://dx.doi.org/10.1111/j.1468-5957.1994.tb00311.x

\section{(cc) $\mathrm{EY}$}

This work is licensed under a Creative Commons Attribution 3.0 License. 